\title{
Nonmalignant pleural lesions due to environmental exposure to asbestos: a field-based, cross-sectional study
}

\author{
M. Metintas*, S. Metintas" ${ }^{\#}$ G. Hillerdal ${ }^{\mp}$, I. Ucgun*, S. Erginel*, \\ F. Alatas* and H. Yildirim*
}

ABSTRACT: The aim of the present study was to investigate the frequencies of asbestos-related benign pleural diseases in villagers environmentally exposed to asbestos and the factors affecting these frequencies.

A field-based, cross-sectional study was designed. In total, 991 villagers from 10 villages, randomly chosen from 67 villages with known use of asbestos-containing white soil in central Anatolia (Turkey), were investigated. The type of asbestos in the white soil was determined for each village, as well as air-borne fibre concentrations. The villagers were investigated with smallsize chest roentgenograms and epidemiological features were recorded.

The air-borne fibre levels were generally low. Despite this, pleural plaques were found in $14.4 \%$ of the villagers, $10.4 \%$ had diffuse pleural fibrosis and $0.4 \%$ asbestosis. The significant variables for plaques were age, sex, type of asbestos fibre, e.g. actinolite and tremolite, and exposure duration, while there was a negative relationship with cumulative exposure. The variables affecting diffuse pleural fibrosis were age, exposure duration and cumulative exposure.

In conclusion, villagers exposed to environmental asbestos have high frequencies of pleural plaques and diffuse pleural fibrosis, similar to occupationally exposed asbestos cohorts. Different types of asbestos appear to result in different frequencies of pleural lesions.

KEYWORDS: Asbestos, environmental exposure, pleura, pleural fibrosis, pleural plaques

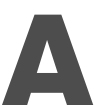
sbestos is a mineral that has been extensively mined and used for a large number of purposes all over the world, but it is now banned in most Western countries because of its many medical effects. The most important of these are different cancers, especially malignant mesothelioma and lung cancer. Apart from malignant diseases, it is also well known that asbestos can cause benign lesions of both the lung parenchyma and the pleura.

Natural deposits of soil mixtures containing asbestos have been reported in many countries, among them Turkey, Greece, Cyprus, Japan, China and New Caledonia [1-10]. Villagers in these mainly agricultural regions can be exposed to asbestos fibres when working in the fields or when using the soil for various purposes, such as white-washing or plastering walls (white stucco), and insulating or waterproofing floors and roofs. The soil has even been used as baby powder and in pottery $[2,4,5]$.

The soil is known in Anatolia (Turkey) as "aktoprak" (white soil) or "çorak", and many deposits exist there. Pleural lesions, parenchymal lesions and malignant mesothelioma frequently occur in these villagers [1, 2, 4-6]. The annual malignant mesothelioma incidence rates have been calculated to be 114.8 per $100,000 \cdot \mathrm{yr}^{-1}$ for males and 159.8 for females in these Turkish rural regions. Thus, the risk of mesothelioma is similar to that in people with heavy occupational exposure to asbestos [6].

The response to inhaled asbestos fibres is affected by many parameters including: physical or chemical characteristics of fibres; cumulative fibre dose; latency; and individual host factors. Previous studies in Anatolia have shown that the fibre types are mainly tremolite, actinolite or a tremolite/actinolite-chrysotile mixture [4-6, 11] The exposure levels are commonly lower than those in occupational settings, but the exposure begins at birth in the villages [5]. Most of the current knowledge on asbestos-related lung diseases comes from occupationally exposed cohorts [12-18]. Since asbestos exposure in the rural areas is different, benign asbestos-related lesions may also be different.
AFFILIATIONS

Depts of ${ }^{*}$ Chest Diseases, and

"Public Health, Osmangazi

University Medical Faculty, Eskisehir,

Turkey.

'Dept of Pulmonology, Karolinska Hospital, Stockholm, Sweden.

CORRESPONDENCE

M. Metintas

Ömerağa mahallesi Adsız Sokak

No:11

26220 Eskisehir

Turkey

Fax: 902222394714

E-mail: metintas@superonline.com

Received:

November 292004

Accepted after revision:

June 282005

SUPPORT STATEMENT

This study was partly supported by the Research Fund of Osmangazi

University, Eskisehir, Turkey. 
In the present study, the frequencies of asbestos-related benign pleural diseases were investigated using conventional radiology in villagers environmentally exposed to asbestos. These findings were related to exposure levels, age, sex, time living in the villages and type of fibre.

\section{MATERIALS AND METHODS Investigated villagers}

For this cross-sectional study, a randomly selected sample of villagers from villages where white soil containing asbestos was still used was required. There are presently 403 villages in the county of Eskisehir (Turkey), and data from earlier studies existed for 196 of these. White soil had been used in 140 of the villages, and is still being used in 126. In total, 67 of the 126 villages were randomly chosen and white soil samples were obtained from them. Tremolite or other types of asbestos fibres were found in 41 villages. A total of 10,120 people are still living in these villages [5]. In the present study, 11 of these 41 villages were randomly chosen. These villages were: Gökdere, Dağküplü, Üçsaray, Kayı, Kadıkuyusu, Tepeköy, Tatarcık, Kayı-M, Sekiören, Ömerköy, and Çalcı. As chest radiographs could not be obtained from all villagers due to weather conditions, which made transport impossible, the village of Kadıkuyusu had to be excluded. Thus, in total, 991 villagers aged $\geqslant 30$ yrs from 10 villages formed the study group.

\section{Exposure assessment}

In the villages, new samples of the white soil utilised by the inhabitants were collected to confirm the presence of asbestos. The mineral analysis was carried out using an x-ray diffractometer. Indoor and outdoor air samples (two samples for each environment) were collected from all villages for minerological and quantitative analyses of asbestos fibres. The indoor samples were taken from a house under quiet conditions (i.e. no brushing or dusting of the floor) where the walls had been white-washed with white soil, and the outdoor samples were taken during the daytime from the centre of the village on the main road (there is usually only one in Turkish villages). The fibre concentrations were determined by experienced specialists at the National Institute of Workers Health and Security (Ankara, Turkey), by counting fibres $>5$ $\mu \mathrm{m}$ in length on the filters using a phase-contrast microscope [19].

\section{Cumulative fibre count for villagers}

It was assumed that a villager spent $8 \mathrm{~h}$ of the day working outside the house, another $8 \mathrm{~h}$ within the house sleeping and resting, and the last $8 \mathrm{~h}$ inside the house carrying out activities other than working. By knowing the air-fibre concentrations outside and inside, the fibre exposure for $24 \mathrm{~h}$ was calculated for each villager. The time spent in the village each year was assumed to be 11 months and, thus, the total time spent in the village until the date of the study and the total fibre exposure could be calculated. Total fibre counts (fibre-yrs $\cdot \mathrm{mL}^{-1}$ ) were calculated in the following way:

$$
\begin{gathered}
((16 \times \text { indoor value }+8 \times \text { outdoor value }) / 24) \\
\times \text { years living in village } \times 11 / 12
\end{gathered}
$$

\section{Investigations}

All villagers completed a questionnaire regarding residence in the village and underwent a clinical and radiological examination with a small-size chest roentgenogram. Of the 991 villagers, 943 (95\%) participated. All roentgenograms were evaluated independently by three chest physicians with experience of asbestos-related lung diseases. Due to a lack of consensus between the physicians, a total of 20 villagers' data were excluded. Consequently, 923 villagers were included in the study. If the small-size chest roentgenogram revealed abnormal or possibly abnormal findings, the villager was recalled for a full-size standard posterior-anterior chest roentgenogram. Five villagers were also examined by computed tomography (CT) scans.

\section{Definitions}

\section{Pleural plaque}

These are circumscribed or discrete, dense pleural opacities or linear structures, localised on the chest wall, diaphragm, pericardium or the mediastinum [20] with a smooth or nodular inner surface. They spare the costophrenic angle and can be calcified. To increase the specificity, strict radiological criteria were used for pleural plaques (PPs) [1, 21, 22], as follows: bilateral lesions $\geqslant 5-\mathrm{mm}$ thick, and/or calcified, well-demarcated, costophrenic angles were not obliterated. The International Labour Office (ILO) classification was not used as it has been shown that it has a low specificity with too many false positives [12, 23].

\section{Diffuse pleural fibrosis}

Diffuse pleural fibrosis (DPF) is a smooth, uninterrupted sheet of pleural thickening extending along at least one-quarter of the chest wall, accompanied by blunting of the costophrenic angle [22-25].

\section{Asbestosis}

If irregular or nodular opacities on lung fields in the chest roentgenogram were found, high-resolution CT was performed. The diagnosis of asbestosis was made if the scans revealed septal thickening, parenchymal linear densities, curvilinear subpleural lines and/or subpleural dependent densities predominantly in the basal zones of the parenchyma, with or without honeycomb appearances and/or visceral pleural thickening $[22,25]$.

\section{Statistical methods}

PP and DPF lesions were dependent variable. Logistic regression was used in the multivariate models to detect the dependent variables (covariates) affecting both of them.

\section{RESULTS}

The white soil samples from the 10 villages all contained asbestos, seven actinolite and tremolite fibres, and three anthophyllite and chrysotile fibres. The mean period of time of living in the village was 51 yrs (median 53, range 27-83 yrs).

Indoor and outdoor air-fibre concentrations were low. Indoor fibre concentrations ranged $0.009-0.28$ fibres $\cdot \mathrm{mL}^{-1}$, with a mean of 0.089 fibres $\cdot \mathrm{mL}^{-1}$. The outdoor fibre concentrations ranged $0.004-0.030$ fibres $\cdot \mathrm{mL}^{-1}$, with a mean of 0.013 fibres $\cdot \mathrm{mL}^{-1}$ (table 1). The cumulative fibre count of the villagers during their 


\begin{tabular}{|c|c|c|c|c|}
\hline & $\begin{array}{c}\text { Indoor } \\
\text { fibres } \cdot \mathrm{mL}^{-1}\end{array}$ & $\begin{array}{l}\text { Outdoor } \\
\text { fibres } \cdot \mathrm{mL}^{-1}\end{array}$ & $\begin{array}{c}\text { Mean } \\
\text { fibres } \cdot \mathrm{mL}^{-1}\end{array}$ & $\begin{array}{l}\text { Cumulative } \\
\text { fibre-yrs } \cdot \mathrm{mL}^{-1}\end{array}$ \\
\hline Samples $n$ & 10 & 10 & & \\
\hline Mean & 0.089 & 0.013 & 0.051 & 2.569 \\
\hline $\begin{array}{l}\text { Standard } \\
\text { error }\end{array}$ & 0.033 & 0.002 & 0.0020 & 0.10 \\
\hline $\begin{array}{l}\text { Standard } \\
\text { deviation }\end{array}$ & 0.10 & 0.0067 & 0.059 & 3.047 \\
\hline Range & $0.009-0.280$ & $0.004-0.020$ & $0.007-0.190$ & $0.190-14.61$ \\
\hline Median & 0.05 & 0.05 & 0.02 & 1.28 \\
\hline
\end{tabular}

lifespan ranged $0.19-14.61$ fibre-yrs $\cdot \mathrm{mL}^{-1}$. Distributions of participants by age, sex and exposure are seen in table 2 .

Among the 923 villagers, 133 (14.4\%) had PP, 96 (10.4\%) DPF and four $(0.4 \%)$ asbestosis. The frequency of PP was significantly higher in males than in females (19.0 and $10.2 \%$, respectively; $p=0.000)$. There was no difference between males and females for DPF (9.5 and 11.3\%, respectively).

Increase of the frequency of PP was significant in both males and females $>60$ yrs of age. In those aged 60-69 yrs compared with those aged 30-39 yrs, the frequency of PP was 6 times higher for males and 3.5 times for females (table 3).

The other feature is that exposure to tremolite/actinolite causes more plaques than exposure to anthophyllite (19.8 and $7.9 \%$, respectively). The frequency of DPF was not affected by the fibre type $(10.7 \%$ for actinolite/tremolite and $10.0 \%$ for anthophillyte). In villagers exposed to actinolite/tremolite, while plaques were related to exposure duration, there was

\section{TABLE 2 Participants by age, sex and exposure}

\begin{tabular}{lrrr} 
Characteristics & Males & Females & Total \\
\hline $\begin{array}{l}\text { Subjects n } \\
\text { Age groups yrs }\end{array}$ & 443 & 480 & 923 \\
$\quad 30-39$ & $62(14.0)$ & $73(15.2)$ & $135(14.6)$ \\
$40-49$ & $64(14.5)$ & $80(16.7)$ & $144(15.6)$ \\
$50-59$ & $79(17.8)$ & $125(26.0)$ & $204(22.1)$ \\
$60-69$ & $153(34.5)$ & $136(28.3)$ & $289(31.3)$ \\
$>69$ & $85(19.2)$ & $66(13.8)$ & $151(16.4)$ \\
Duration of exposure yrs & & & \\
$30-39$ & $85(19.2)$ & $98(20.4)$ & $183(19.8)$ \\
$40-49$ & $75(16.9)$ & $106(22.1)$ & $181(19.6)$ \\
$>49$ & $283(63.9)$ & $276(57.5)$ & $559(60.6)$ \\
Cumulative exposure & & & \\
fibre-yrs $\cdot \mathbf{m L}^{-1}$ & & & \\
$<1.99$ & $258(58.2)$ & $303(63.1)$ & $561(60.8)$ \\
$2-4.99$ & $127(28.7)$ & $106(22.1)$ & $233(25.2)$ \\
$>4.99$ & $58(13.1)$ & $71(14.8)$ & $129(14.0)$ \\
\hline
\end{tabular}

Data are presented as $n(\%)$. an inverse relationship between the frequency of PP and cumulative exposure. The same relationship was not observed for villagers exposed to anthophyllite. The DPF risk increased both with exposure duration and cumulative dose (table 4).

The multivariate analysis showed that the effective variables for PP were sex, exposure duration, type of fibre and cumulative exposure. In individuals who had an exposure duration of $\geqslant 60$ yrs, the rate of PP was 7.7 times higher than in individuals whose exposure was $<39$ yrs. The prevalence of $\mathrm{PP}$ in individuals who had contact with the white soil containing actinolite and tremolite was 4.8 times higher than those who used anthophyllite. The rate of PP among males was 1.76 times higher than that of females. Another significant variable for PP was cumulative exposure (table 5).

The variables affecting DPF were exposure duration and cumulative exposure (table 5).

\section{DISCUSSION}

The response to inhaled asbestos fibres depends on many complex factors including fibre type and size, cumulative fibre dose, individual host factors and latency $[12,25]$. Compared with strictly defined pleural plaques, DPF is more unspecific and may be found after any type of pleuritis [23, 24]. The sensitivity of conventional chest roentgenograms in the detection of pleural and/or pulmonary abnormalities caused by asbestos is relatively low [1, 12, 21, 26, 27]; however, by using strict criteria, the specificity is acceptably high [28]. Thus, the prevalence figures are minimum and the "true" figures should be higher; only the larger plaques are diagnosed but with a high degree of specificity.

There are important differences between exposure in the occupational and in the environmental settings. The white soil in rural areas contains mainly tremolite asbestos. Exposure begins at birth and environmental exposure levels are generally lower than occupational ones. However, the cumulative exposure might be the same or even higher than in occupational settings. In the present study, the cumulative amount of fibres for the villagers in their lifetime was estimated to be between 0.19 and 14.61 fibre-yrs $\cdot \mathrm{mL}^{-1}$. Workplace measurements in the 1960s often showed peak exposures of 20 fibres $\cdot \mathrm{mL}^{-1}$ that were substantially reduced over subsequent years $[12,26]$. In a recent study, annual malignant pleural mesothelioma incidence rates for both sexes were found to be extremely high in the villages (114.8 and 159.8 out of 100,000 for males and females, respectively), as high, in fact, as those observed in occupationally exposed cohorts [6]. The current authors concluded that it would be useful to investigate the frequency of asbestos-related benign lung diseases in the villages and relate them to various factors, such as exposure, fibre type, etc. The present data are thought to be the first from such a cohort in the English literature.

The villages were randomly selected and are probably representative of "white soil-using villages", and study participation was $95 \%$; thus, the authors believe the data to be valid. To increase specificity in the present study, all chest roentgenograms were interpreted independently by physicians who have considerable experience in asbestos-related lung diseases. 


\section{TABLE 3 Lesions by age and sex}

\begin{tabular}{|c|c|c|c|c|c|c|c|c|}
\hline \multirow{2}{*}{$\begin{array}{l}\text { Age groups } \\
\text { yrs }\end{array}$} & \multicolumn{4}{|c|}{ Male } & \multicolumn{4}{|c|}{ Female } \\
\hline & \multicolumn{2}{|c|}{ Pleural plaque } & \multicolumn{2}{|c|}{ Diffuse pleural fibrosis } & \multicolumn{2}{|c|}{ Pleural plaque } & \multicolumn{2}{|c|}{ Diffuse pleural fibrosis } \\
\hline $30-39$ & 6.5 & 1 & 1.6 & 1 & 5.5 & 1 & 2.7 & 1 \\
\hline $60-69$ & 25.5 & $5.9(2.0-17.4)^{*}$ & 12.4 & $11.5(1.5-88.4)^{\star}$ & 14.7 & $3.5(1.1-10.7)^{\star}$ & 14.0 & $6.6(1.5-29.4)^{\star}$ \\
\hline$>69$ & 25.9 & $6.0(1.9-18.7)^{*}$ & 12.9 & $12.1(1.5-96.6)^{\star}$ & 18.2 & $4.7(1.4-15.4)^{\star}$ & 15.2 & $7.8(1.6-37.3)^{\star}$ \\
\hline
\end{tabular}

OR: odds ratio; $\mathrm{Cl}$ : confidence interval. *: $\mathrm{p}<0.05$.

The low sensitivity using strict criteria for PP can be seen as disadvantage giving a fairly low prevalence. In the present study, the prevalence of PPs was similar to that in other studies from Turkey [2, 4, 11]. In China, villagers aged $>40$ yrs who were exposed to crocidolite asbestos had a PP frequency of $20 \%$ [7]. However, in Northeast Corsica, in residents aged $>50$ yrs, it was $41 \%$ [8]. Thus, the PP prevalence varies highly in different cohorts. The radiological method (chest roentgenogram or thoracic CT), criteria used and experience of the reader all play a role in this variation. Apart from this, factors such as age, sex, type of fibre, dose level and length of exposure affect the risk of PP. In the current study, the risk of PP was associated with increasing age, males, type of fibre (tremolite or actinolite) and measured dust level.
In the literature, it is generally accepted that plaques are more related to time after first exposure than to the dose. PPs have a long latency time and are not found $<10 \mathrm{yrs}$, and seldom $<20$ yrs, after the first exposure to asbestos, with most appearing only after $30 \mathrm{yrs}[12,13,29]$. Consequently, the frequency of PP increases with increasing age. For environmental exposure, where the population is exposed from birth, the first pleural changes will appear after $30 \mathrm{yrs}$ of age and the prevalence of plaques increases with increasing age. In Matsubase, a town in Japan with environmental exposure to anthophyllite, the PP frequency in the eighth decade was 8 times higher than in the fourth decade [9]. The PP frequency in the current study matched well with previous data; thus, in the group aged 30-39 yrs, it was 5.9\%, and in those aged 60-69 yrs

TABLE 4 Distribution of pleural plaque and diffuse pleural fibrosis prevalence rates according to fibre type, exposure duration, cumulative exposure and sex

\begin{tabular}{|c|c|c|c|c|c|c|}
\hline & \multicolumn{3}{|c|}{ Actinolite/tremolite } & \multicolumn{3}{|c|}{ Anthophyllite } \\
\hline & Male & Female & Total & Male & Female & Total \\
\hline \multicolumn{7}{|c|}{ Duration of exposure yrs } \\
\hline 30-39 & 11.5 & 5.9 & 8.3 & & 3.3 & 1.6 \\
\hline \multicolumn{7}{|c|}{ Cumulative exposure fibre-yrs $\cdot \mathrm{mL}^{-1}$} \\
\hline$<1.99$ & 32.3 & 18.0 & 24.2 & 8.2 & 5.7 & 6.9 \\
\hline $2-4.99$ & 30.2 & 12.7 & 22.8 & 14.6 & 9.3 & 11.9 \\
\hline$>4.99$ & $12.3^{*}$ & $5.6^{*}$ & $8.6^{*}$ & & & \\
\hline \multicolumn{7}{|c|}{ Diffuse pleural fibrosis } \\
\hline \multicolumn{7}{|c|}{ Duration of exposure yrs } \\
\hline$<1.99$ & $1.0^{*}$ & 8.6 & $5.3^{*}$ & $7.5^{\star}$ & 8.6 & $8.1^{*}$ \\
\hline $2-4.99$ & 15.1 & 11.1 & 13.4 & 19.5 & 16.3 & 17.9 \\
\hline$>4.99$ & 14.0 & 19.7 & 17.2 & & & \\
\hline
\end{tabular}

Data are presented as \%. *: $p<0.05$ 


\begin{tabular}{|c|c|c|c|}
\hline \multirow{2}{*}{$\begin{array}{l}\text { TABLE } 5 \\
\text { Factors }\end{array}$} & \multicolumn{3}{|c|}{$\begin{array}{l}\text { Logistic regression analysis to predict pleural } \\
\text { plaque and diffuse pleural fibrosis in villagers } \\
\text { environmentally exposed to asbestos }\end{array}$} \\
\hline & & Pleural plaque & Diffuse pleural fibrosis \\
\hline \multicolumn{4}{|l|}{ Sex } \\
\hline Female & & 1 & 1 \\
\hline Male & & $1.76(1.17-2.64)^{\star}$ & $0.90(0.58-1.39)$ \\
\hline \multicolumn{4}{|c|}{ Exposure duration yrs } \\
\hline $20-39$ & & 1 & 1 \\
\hline $40-49$ & & $1.99(0.89-4.46)$ & $3.46(1.33-8.97)^{*}$ \\
\hline $50-59$ & & $3.95(1.96-7.97)^{\star}$ & $5.35(2.21-12.97)^{\star}$ \\
\hline$\geqslant 60$ & & $7.73(3.78-15.78)^{*}$ & $6.64(2.65-16.61)^{*}$ \\
\hline \multicolumn{4}{|c|}{ Asbestos fibre contamination } \\
\hline Anthophyllit & & 1 & 1 \\
\hline Actinolite ar & d tremolite & $4.84(3.06-7.65)^{\star}$ & $1.28(0.78-2.11)$ \\
\hline \multicolumn{4}{|c|}{ Cumulative dose } \\
\hline$<5$ fibre-yrs & $m L^{-1}$ & 1 & 1 \\
\hline$\geqslant 5$ fibre-yrs & $\cdot m L^{-1}$ & $0.33(0.17-0.67)^{\star}$ & $1.83(1.007-3.35)^{\star}$ \\
\hline
\end{tabular}

it was $20.4 \%$. Even a low level of exposure to asbestos and intermittant exposures can cause PP $[12,30]$. The doseresponse relationship for PPs is much weaker than that for parenchymal asbestosis, even if longer and heavier exposure will lead to more extensive plaques [10, 14-16].

DPF is less common than plaques, but there are no good studies on its prevalence [29]. The prevalence rate of DPF was found to be $10.4 \%$ and the risk increased with cumulative dose and increasing age, with $2.2 \%$ in those aged $30-39$ yrs and $13.2 \%$ in those aged $60-69$ yrs. These findings are in agreement with those of other studies and indicate that the present study method of measuring cumulative exposure is valid.

The inverse relationship between PP and cumulative exposure is not easy to explain. One possibility is that with increasing cumulative exposure, DPF becomes more common and the lesions of DPF will obscure the plaques. Thus, it could be a "false" finding. However, these findings strongly suggest that the aetiopathogenesis of PPs and DPF is different.

Our way of measuring exposure is fairly crude. The few measurements taken recently might not mirror historical exposures, but it is unlikely that the technique of whitewashing houses is different today than techniques used in previous years. During white-washing or brushing of the floor, the air levels are much higher [18]. Such peak levels might be more important than a continuous low-level exposure, but it is not possible to reconstruct such exposures on the personal level. The fact that DPF was found to be related to total exposure while PP was not indicates that the authors' way of measuring total exposure, at least to some extent, mirrors the true exposure. In a case report from Belgium, concerning a man from a Turkish village with no known occupational exposure, there was a high level of asbestos bodies in the bronchoalveolar lavage, in fact as much as can be seen in occupational exposure [31]. However, if such heavy exposure had been the rule in the study villagers, there ought to be a higher incidence of asbestosis.

The PP prevalence varied with the particular exposure, suggesting a different effect from various fibres [13]. In a recent study, the age-adjusted risk for PP was found to be higher for high concentrations of crocidolite/amosite fibres than for anthophyllite fibres [16]. This is in agreement with the present finding that tremolite/actinolite fibres are more prone to cause PP than anthophyllite and chrysotile.

Actinolite is very similar to tremolite and differentiation of the fibres by optical microscopy is not possible [32, 33]. Commercial mining of actinolite asbestos is practically unknown [32]. Tremolite has never been mined on a large scale, but is a common contaminant of chrysotile [34]. Tremolite and actinolite are present as soil constituents in large areas around the Mediterranean Sea (Turkey, Greece, Cyprus, Corsica) and in New Caledonia. Tremolite and actinolite may also be present in chrysotile, talc, dolomite, limestone and vermiculate ores. The possibility that actinolite can cause $\mathrm{PP}$ is strongly suggested by the current study.

In this study, a low prevalence of asbestosis $(0.4 \%)$ was found. This was expected since cumulative exposure was 14 fibre$\mathrm{yrs} \cdot \mathrm{mL}^{-1}$. The generally accepted threshold limit level for asbestosis is 25 fibre-yrs $\cdot \mathrm{mL}^{-1}[15,35]$.

In conclusion, the frequency of pleural plaques and diffuse pleural fibrosis was found to be similar to those found in occupational exposure, as was the mesothelioma incidence rate reported previously [7]. The risk of diffuse pleural fibrosis is also dependant on the cumulative dose, but this is not true of pleural plaques. Although there is no difference between mesothelioma and diffuse pleural fibrosis with respect to sex, there was a higher prevalence of pleural plaques in males.

\section{REFERENCES}

1 Hillerdal G. The human evidence: parenchymal and pleural changes. Ann Occup Hyg 1994; 38: 561-567.

2 Baris YI, Bilir N, Artvinli M, et al. An epidemiological study in an Anatolian village environmentally exposed to tremolite asbestos. Br J Ind Med 1988; 45: 838-840.

3 McConnochie K, Simonato L, Mavrides P, Christofides P, Pooley FD, Wagner JC. Mesothelioma in Cyprus: the role of tremolite. Thorax 1987; 42: 342-347.

4 Yazicioglu S, Ilcayto R, Balci K, Sayli BS, Yorulmaz B. Pleural calcification, pleural mesotheliomas and bronchial cancers caused by tremolite dust. Thorax 1980; 35: 564-569.

5 Metintas M, Özdemir N, Hillerdal G, et al. Environmental asbestos exposure and malignant pleural mesothelioma. Respir Med 1999; 93: 349-353.

6 Metintas S, Metintas M, Ucgun I, Oner U. Malignant mesothelioma due to environmental exposure to asbestos: follow-up of a Turkish cohort living in a rural area. Chest 2002; 122: 2224-2229.

7 Luo S, Liu X, Mu S, Tsai SP, Wen CP. Asbestos related diseases from environmental exposure to crocidolite in Da-yao, China. I. Review of exposure and epidemiological data. Occup Environ Med 2003; 60: 35-42. 
8 Rey F, Boutin C, Viallat JR, et al. Environmental asbestotic pleural plaques in northeast Corsica: correlations with airborne and pleural mineralogic analysis. Eur Respir J 1993; 6: 978-982.

9 Murai Y, Kitagawa M, Hiraoka T. Fiber analysis in lungs of residents of a Japanese town with endemic pleural plaques. Arch Environ Health 1997; 52: 263-269.

10 Hillerdal G. Pleural plaques: incidence and epidemiology, exposed workers and the general population. Indoor Built Environ 1997; 6: 86-95.

11 Karakoca Y, Emri S, Cangır AK, Baris YI. Environmental pleural plaques due to asbestos and fibrous zeolite exposure in Turkey. Indoor Built Environ 1997; 6: 100-105.

12 Hillerdal G, Henderson DW. Asbestos, asbestosis, pleural plaques and lung cancer. Scand J Work Environ Health 1997; 23: 93-103.

13 Nishimura SL, Broaddus VC. Asbestos-induced pleural disease. Clin Chest Med 1998; 19: 311-329.

14 Kishimoto T, Ono T, Okada K, Ito H. Relationship between number of asbestos bodies in autopsy lung and pleural plaques on chest x-ray film. Chest 1989; 95: 549-552.

15 Bégin R, Christmas JW. Detailed occupational history. Am J Respir Crit Care Med 2001; 163: 598-599.

16 Karjalainen A, Karhunen PJ, Lalu K, et al. Pleural plaques and exposure to mineral fibres in a male urban necropsy population. Occup Environ Med 1994; 51: 456-460.

17 Kishimoto T, Morinaga K, Kira S. The prevalence of pleural plaques and/or pulmonary changes among construction workers. Am J Ind Med 2000; 37: 291-295.

18 Baris YI. Asbestos and erionite related chest diseases. Ankara, Semih Ofset Mat Ltd Com., 1987; pp. 18-79.

19 WHO Library Cataloguing in Publication Data. Determination of airborne fibre number concentrations: a recommended method, by phase-contrast optical microscopy (membrane filter method). Geneva, World Health Organization Publications, 1997; pp. 5-36.

20 Statement of the American Thoracic Society. The diagnosis of non malignant diseases related to asbestos. Am Rev Respir Dis 1986; 134: 363-368.

21 Hillerdal G. Pleural plaques and risk for bronchial carcinoma and mesothelioma. A prospective study. Chest 1994; 105: 144-150.

22 Gevenois PA, de Maertelaer V, Madani A, et al. Asbestosis, pleural plaques and diffuse pleural thickening: three distinct benign responses to asbestos exposure. Eur Respir J 1998; 11: 1021-1027.

23 Hillerdal G. Pleural lesions and the ILO classification: the need of a revision. Am J Ind Med 1991; 19: 125-130.

24 Hillerdal G, Malmberg P, Hemmingsson A. Asbestos related lesions of the pleura: parietal plaques compared to diffuse thickening studied with chest roentgenography, computed tomography, lung function, and gas exchange. Am J Ind Med 1990; 18: 627-639.

25 Rudd RM. New developments in asbestos-related pleural disease. Thorax 1996; 51: 210-216.

26 Hillerdal G. Mesothelioma: cases associated with nonoccupational and low dose exposures. Occup Environ Med 1999; 56: 505-513.

27 Al Jarad N, Poulakis N, Pearson MC, et al. Assessment of asbestos-induced pleural disease by computed tomography-correlation with chest radiograph and lung function. Respir Med 1991; 85: 203-208.

28 Hillerdal G, Lindgren A. Pleural plaques: correlation of autopsy findings to radiographic findings and occupational history. Eur J Respir Dis 1980; 61: 315-319.

29 Hillerdal G. Asbestos-related pleural disease including diffuse malignant mesothelioma. In: Loddenkemper $\mathrm{R}$, Antony VB, eds. Pleural Diseases. Eur Respir Mon 2002; 22: pp. 189-203.

30 Becklake M, Case B. Fiber burden and asbestos-related lung disease: determinants of dose-response relationships. Am J Respir Crit Care Med 1994; 150: 1488-1492.

31 De Vuyst P, Dumortier P, Gevenois PA. Analysis of asbestos bodies in BAL from subjects with particular exposures. Am J Ind Med 1997; 31: 669-704.

32 Ross M. The geologic occurrences and health hazards of amphibole and serpentine asbestos. In: Skinner HCW, Ross M, Frondel C, eds. Asbestos and Other Fibrous Materials. New York, Oxford University Press, 1988; pp. 279-309.

33 World Health Organization. Asbestos and other natural mineral fibres. Geneva, WHO Publications, 1987.

34 Selçuk ZT, Çöplü L, Emri S, et al. Malignant pleural mesothelioma due to environmental mineral fiber exposure in Turkey: analysis of 135 cases. Chest 1992; 102: 790-796.

35 Peto J, Doll R, Hermon C, et al. Relationship of mortality to measures of environmental asbestos pollution in an asbestos textile factory. Ann Occup Hyg 1985; 29: 305-355. 